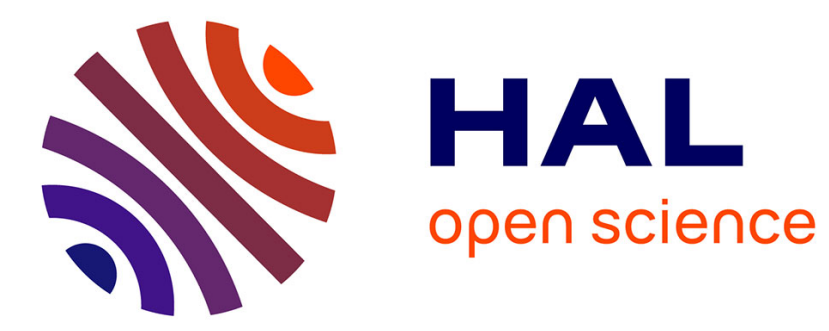

\title{
Petri Net Synthesis
}

Eric Badouel, Luca Bernardinello, Philippe Darondeau

\section{To cite this version:}

Eric Badouel, Luca Bernardinello, Philippe Darondeau. Petri Net Synthesis. Springer, pp.339, 2015, Text in Theoretical Computer Science, an EATCS Series, M. Henzinger, J. Hromkovic, M. Nielsen, G. Rozenberg, A. Salomaa, 978-3-662-47966-7. 10.1007/978-3-662-47967-4 . hal-01237142

\section{HAL Id: hal-01237142 \\ https://hal.inria.fr/hal-01237142}

Submitted on 2 Dec 2015

HAL is a multi-disciplinary open access archive for the deposit and dissemination of scientific research documents, whether they are published or not. The documents may come from teaching and research institutions in France or abroad, or from public or private research centers.
L'archive ouverte pluridisciplinaire HAL, est destinée au dépôt et à la diffusion de documents scientifiques de niveau recherche, publiés ou non, émanant des établissements d'enseignement et de recherche français ou étrangers, des laboratoires publics ou privés. 


\section{Texts in Theoretical Computer Science An EATCS Series}

Editors: M. Henzinger J. Hromkovič M. Nielsen G. Rozenberg A. Salomaa

Founding Editors: W. Brauer G. Rozenberg A. Salomaa

On behalf of the European Association

for Theoretical Computer Science (EATCS)

Advisory Board:

S. Albers H. Attiya G. Ausiello M. Broy C. Calude A. Condon A. Czumaj P. Degano J. Diaz P. Gastin G. Gottlob D. Harel J. Hartmanis R. Heckel L.A. Hemaspaandra T. Henzinger M. Hermenegildo B. Jonsson J. Karhumäki L. Kari M. Koutny D. Kozen T. Leighton H. Lin G. Mauri M. Nivat D. Niwiński C. Papadimitriou D. Peleg D. Sannella U. Schöning D. Scott P.G. Spirakis D. Wagner E. Welzl M. Wirsing 

Eric Badouel • Luca Bernardinello Philippe Darondeau

\section{Petri Net Synthesis}

算 Springer 


\author{
Eric Badouel \\ IRISA/INRIA Rennes - \\ Bretagne Atlantique \\ Rennes, France
}

Philippe Darondeau

IRISA/INRIA Rennes -

Bretagne Atlantique

Rennes, France

\section{Series Editors \\ Monika Henzinger \\ Faculty of Science \\ Universität Wien \\ Wien, Austria}

Mogens Nielsen

Department of Computer Science

Aarhus Universitet

Aarhus, Denmark

Arto Salomaa

Turku Centre of Computer Science

Turku, Finland
Luca Bernardinello

DISCO

Università degli Studi di Milano-Bicocca

Milano, Italy

\author{
Juraj Hromkovič \\ ETH Zentrum \\ Department of Computer Science \\ Swiss Federal Institute of Technology \\ Zürich, Switzerland
}

Grzegorz Rozenberg

Leiden Centre of Advanced

Computer Science

Leiden University

Leiden, The Netherlands

ISSN 1862-4499

Texts in Theoretical Computer Science. An EATCS Series

$\begin{array}{lll}\text { ISBN 978-3-662-47966-7 } & \text { ISBN 978-3-662-47967-4 (eBook) } \\ \text { DOI 10.1007/978-3-662-47967-4 } & & \end{array}$

Library of Congress Control Number: 2015951435

Springer Heidelberg New York Dordrecht London

(C) Springer-Verlag Berlin Heidelberg 2015

This work is subject to copyright. All rights are reserved by the Publisher, whether the whole or part of the material is concerned, specifically the rights of translation, reprinting, reuse of illustrations, recitation, broadcasting, reproduction on microfilms or in any other physical way, and transmission or information storage and retrieval, electronic adaptation, computer software, or by similar or dissimilar methodology now known or hereafter developed.

The use of general descriptive names, registered names, trademarks, service marks, etc. in this publication does not imply, even in the absence of a specific statement, that such names are exempt from the relevant protective laws and regulations and therefore free for general use.

The publisher, the authors and the editors are safe to assume that the advice and information in this book are believed to be true and accurate at the date of publication. Neither the publisher nor the authors or the editors give a warranty, express or implied, with respect to the material contained herein or for any errors or omissions that may have been made.

Printed on acid-free paper

Springer-Verlag GmbH Berlin Heidelberg is part of Springer Science+Business Media (www.springer.com) 
This book is dedicated to the memory of our friend Philippe Darondeau. 



\section{Foreword}

A Petri net synthesis problem can be seen as a model transformation from a behavioural to a structural description of a concurrent system. In its original version formulated by Andrzej Ehrenfeucht and myself, the behavioural description was given by transition systems and the structural description was given by elementary net systems. The solution we provided was based on the theory of regions of transition systems which also yielded an automatic synthesis of an elementary net system whose behaviour was captured by a given transition system.

Since then (1989) Petri net synthesis has become a very vivid and successful research area. The original approach was extended at both ends: the behavioural and the structural descriptions. The acceptable behavioural specifications were extended to, for example, formal languages and execution traces. The structural descriptions were extended first to Place/Transition nets and then to, for example, Petri Nets augmented with priorities or inhibitor arcs. Also, the types of operational semantics were extended to, for example, step sequence semantics (where several actions can be executed simultaneously) which can be constrained by various firing policies (such as maximal parallelism). The notion of a region (suitably adapted) proved to be robust in all these extensions - as a matter of fact it became a basic/central notion of the framework of Petri nets and beyond. All these research efforts were accompanied by the development of suitable algorithms for net synthesis.

Application areas of net synthesis currently cover, among others, the construction of distributed systems, supervisory control, process discovery, and the design of asynchronous circuits. One can already identify the influence of net synthesis research on the design of asynchronous circuits operating under relative timing, and process mining technologies aimed at understanding causal relationships in the behaviour of complex business systems.

Altogether Petri net synthesis has become a full-fledged, relevant, and exciting research area. This book provides an impressive in-depth account of a wide range of the existing results and techniques. It extensively covers the theory and the algorithms and it also provides a good insight into applications. The book is an impressive achievement that will be very valuable for both novices entering this research field and for researchers in this area as a rich and reliable reference as well as a source of relevant research problems.

The very high technical and presentation quality of the book is certainly due to the fact that all three authors made fundamental contributions to this research area. Unfortunately, Philippe Darondeau passed away much too early, so that he could not see the final product of this project. The book is a tribute to this outstanding and inspiring researcher.

Grzegorz Rozenberg

Leiden, The Netherlands 2015 



\section{Preface}

The synthesis problem for Petri nets consists in building a Petri net satisfying a given behavioural specification. In its applications, quite often the initial specification is inherently sequential, and part of the problem consists in eliciting potential concurrence.

This book aims at giving a comprehensive and systematic survey of the synthesis problem and of region theory, which underlies its solution.

Region theory arose from the work by Ehrenfeucht and Rozenberg on 2structures, starting from the late 1980s. A 2-structure is a special case of a labelled transition system, where labels denote actions producing state changes. A region in a 2-structure (or in a transition system) is a subset of states whose "frontier" is uniformly crossed, or not crossed, by all occurrences of the same label.

In the marking graph of an elementary Petri net, the extension of a place (or condition) is a region. Ehrenfeucht and Rozenberg showed that the set of all regions of a transition system serve as the places of a net whose marking graph is isomorphic to the given transition system, provided the latter satisfies a set of axioms, which can be checked by computing the set of regions.

Since then, the synthesis problem and the theory of regions have attracted several researchers. The original notions have been extended, generalized, and adapted to different classes of Petri nets, and to different initial specifications, other than transition systems.

The algebraic properties of several variants of the original notion of regions have been extensively studied, and some software tools have been developed which solve the synthesis problem.

Eric Badouel was first introduced to the theory of regions by a tutorial given by P.S. Thiagarajan at a Summer School in Gargnano, Italy, which was coorganized by Luca Bernardinello. In his talk P.S. Thiagarajan presented a joint work with Mogens Nielsen and Grzegorz Rozenberg on the use of regions to relate some models of concurrency. This was a source of inspiration for introducing a variant of regions for the characterization of trace automata defined by structural operational specifications. This work, done jointly with Philippe Darondeau, was the starting point for a long and fruitful collaboration.

Around the same period Jörg Desel and Wolfgang Reisig wrote a survey on the synthesis problem of Petri nets, Luca Bernardinello showed the central rôle played by minimal regions and Giorgio De Michelis applied net synthesis techniques in the context of workflow management systems.

In retrospect, the origins of this book can be traced back to a meeting held in 1992 in Leiden, The Netherlands, during a REX Concurrency Day, where the above-mentioned persons were invited by Grzegorz Rozenberg to exchange 
ideas on region theory. This meeting marked the start of the collaboration on this subject among the three authors. Later, this collaboration was strengthened when Luca moved to Rennes to join Eric and Philippe for a year and a half.

A first comprehensive survey of the field was written by Eric Badouel and Philippe Darondeau in 1998, but the flow of publications on the subject remained steady, showing a combination of theoretical and application-oriented interest.

The vitality of the field, more than twenty years since its birth, is witnessed by the series of ART (Applications of Region Theory) workshops, held in 2010, 2011, and 2013. The topic has been nurtured by the contributions of many researchers including among others Eike Best, Benoît Caillaud, Josep Carmona, Jordi Cortadella, Raymond Devillers, Michael Kishinevsky, Jetty Kleijn, Alex Kondratyev, Maciej Koutny, Luciano Lavagno, Robert Lorenz, Marta Pietkiewicz-Koutny, and Alex Yakovlev.

Writing this book has followed a long process. It was started at the end of 2010 by Eric and Philippe. A first draft of the book was almost completed by the end of 2012, when Philippe had knowledge that he was suffering from a cancer that would leave him little time to live. At this point, Luca joined the team. Philippe passed away on Monday March 18th, 2013. He fought a courageous battle, and remained active until the very end. His pain was strong during his last days, but he wanted to complete his contribution to this book.

With the loss of a dear friend and colleague and the completion of this book we are aware that we are closing a period of our lives rich in experiences and emotions. We hope that this book will be an opportunity for others to open new pages.

As authors, we gratefully acknowledge the support by Springer, and particularly by Ronan Nugent, who has backed the book project throughout its drafting. A warm thank goes to the anonymous referees and to the copy editor, whose contribution has significantly improved the quality of the book.

Finally, a special thank goes to Grzegorz Rozenberg, who kindly agreed to write a foreword, and who has always been a source of inspiration and of encouragement.

Eric Badouel, Rennes, France

Luca Bernardinello, Milano, Italy

2015 


\section{Contents}

Introduction .................................. 1

\section{Part I Elementary Net Synthesis}

1 Introduction to Elementary Net Synthesis . . . . . . . . . . 15

1.1 An Informal Introduction to Elementary Nets ............ 15

1.2 Elementary Net Systems and Their Firing Rule .......... 17

1.3 Regions and Elementary Transition Systems ........... 24

1.4 Admissible Sets of Regions and the Separation Axioms ...... . 35

1.5 Minimal Regions Are Sufficient for Synthesis . . . . . . . . . . . 42

1.6 Minimal Admissible Sets of Regions.................... 45

1.7 Regions and State Machine Decompositions ............ 48

1.8 Regions of Labelled Partial 2-Structures $\nmid \ldots \ldots \ldots \ldots \ldots \ldots . \ldots 1$

Problems ................................... 56

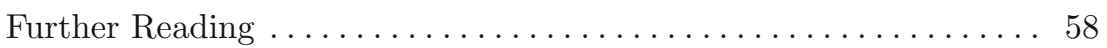

2 Other Forms of the Synthesis Problem.............. 59

2.1 Canonical Net Versions Yield Optimal Realizations .......... 59

2.2 Relaxing the State Separation Property .............. 66

2.3 Net Synthesis from Languages . .................. 72

2.4 Minimal Regions and Approximate Synthesis ............ 78

2.5 Minimal Regions and Synthesis up to Language Equivalence .. 80 Problems ................................ 81

$3 \quad$ Algorithms of Elementary Net Synthesis ............ 83

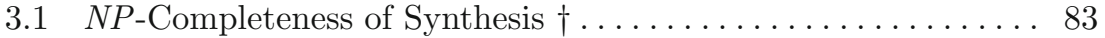

3.1.1 The Separation Problems Are NP-Complete........ 84

3.1.2 The Elementary Net Synthesis Problem Is NP-Complete 87

3.2 Algorithms of Elementary Net Synthesis . . . . . . . . . . . . 90

3.2 .1 Rough Sets .......................... 91 
3.2.2 Signatures of Rough Sets . . . . . . . . . . . . . . . . . 95

3.2 .3 Rough Regions........................ 98

3.2.4 Extracting Regions from a Rough Region............ 101

3.2.5 Net Synthesis Algorithms..................... 103

3.2.6 The Heuristic Approach of Petrify . . . . . . . . . . . . 107

Problems .................................... 109

\section{Part II Types of Nets}

4 Variations of Elementary Net Synthesis .............. 121

4.1 The Synthesis of Event/Condition Nets . . . . . . . . . . . 121

4.2 Types of Nets ................................ 129

4.3 Regions as Morphisms and Synthesized Nets ............. 136

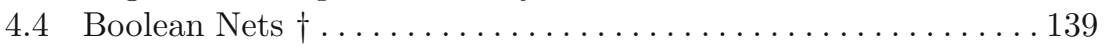

Problems .................................. 147

$5 \quad$ A Unified Theory of Net Synthesis ................. 153

5.1 Duality Between Nets and Transition Systems............ 155

5.2 Representation Results ......................... 160

5.3 Taking Concurrency into Account $\dagger \ldots \ldots \ldots \ldots \ldots \ldots \ldots . \ldots 164$

5.3.1 Transition Systems with a Concurrency Relation ....... 165

5.3 .2 Step Transition Systems........................ . 169

Problems ..................................... 177

Further Reading ............................. 181

\section{Part III P/T-Net Synthesis}

6 The Linear Algebraic Structure of Regions . . . . . . . . . 187

6.1 Flip-Flop Net Synthesis . . . . . . . . . . . . . . . . . . 187

6.2 Introduction to $\mathrm{P} / \mathrm{T}-\mathrm{Nets}$ and $\mathrm{P} / \mathrm{T}$-Regions ............ 194

6.3 Algebraic Structure of $\mathrm{P} / \mathrm{T}$-Regions . . . . . . . . . . . . . . 198

Problems ......................................210

7 Synthesis of $\mathrm{P} / \mathrm{T}-\mathrm{Nets}$ from Finite Initialized Transition

Systems .................................... 213

7.1 Exact Synthesis of Pure P/T-Nets . . . . . . . . . . . . . . 213

7.2 Approximate Synthesis of Pure P/T-Nets . . . . . . . . . . 218

7.3 Synthesis of Impure P/T-Nets . . . . . . . . . . . . . . 220

7.4 Synthesis of Bounded Nets from Regular Languages.......... 221

7.5 Synthesis of Pure and Bounded Nets from Finite Languages .. 222

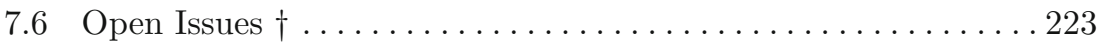

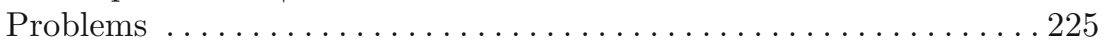




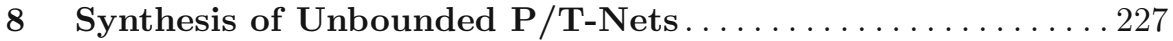

8.1 Rational Sets and Semilinear Sets . . . . . . . . . . . . . . . . . . 227

8.2 Unbounded P/T-Regions of Languages . . . . . . . . . . . . . . 230

8.3 Synthesis of Unbounded P/T-Nets from Languages . . . . . . . . . . 234

8.4 Unbounded P/T-Regions of Transition Systems † . . . . . . . . . 238

8.5 Synthesis of Nets from Infinite Transition Systems $\dagger$. . . . . . . 246

$9 \quad \mathbf{P} /$ T-Nets with the Step Firing Rule $\dagger \ldots \ldots \ldots \ldots \ldots \ldots 253$

9.1 Regions of Step Transition Systems . . . . . . . . . . . . . . . . . . 254

$9.2 \mathrm{P} / \mathrm{T}-\mathrm{Net}$ Realization of Finite Step Transition Systems . . . . . . . 255

$9.3 \mathrm{P} / \mathrm{T}-$ Net Realization of Step Languages . . . . . . . . . . . . . . . . . 259

9.4 Partial Languages and Token Flows . . . . . . . . . . . . . . . 260

\section{Part IV Applications of Net Synthesis}

10 Extracting Concurrency from Transition Systems † . . . . . 269

10.1 Distributed Realization of Transition Systems . . . . . . . . . . . 269

10.1.1 Distributed Transition Systems . . . . . . . . . . . . . . 270

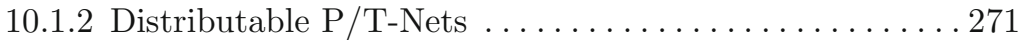

10.1.3 Splitting a Distributable Net into Pieces. . . . . . . . . . 273

10.1.4 Distributed Implementation of a Transition System . . . . 273

10.1.5 Synthesizing Distributable P/T-Nets . . . . . . . . . . 276

10.2 Compacting Automata and Products of Automata . . . . . . . . 279

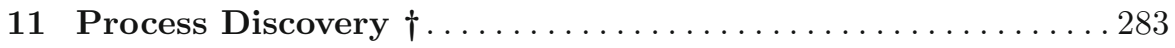

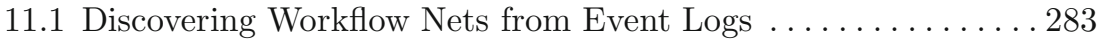

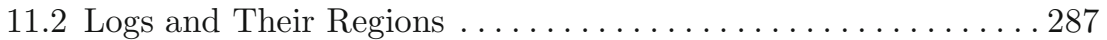

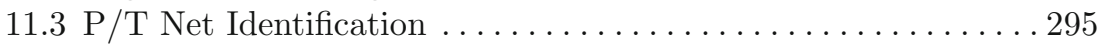

Problems . . . . . . . . . . . . . . . . . . . . . . . 297

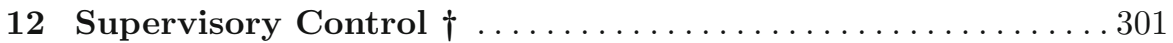

12.1 Ramadge and Wonham's Theory of Supervisory Control . . . . . . 301

12.2 Petri Net Supervisory Control . . . . . . . . . . . . . . . . . . . . . . 304

12.3 Region-Based Supervisory Control of Petri Nets . . . . . . . . . . . 305

12.4 Region-Based Supervisory Control of Discrete Event Systems . 312

12.5 Distributed Control of Discrete Event Systems . . . . . . . . . . 315

13 Design of Speed Independent Circuits $\dagger \ldots \ldots \ldots \ldots \ldots$

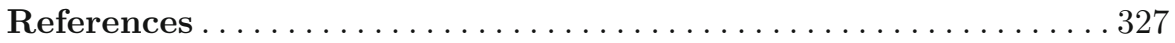

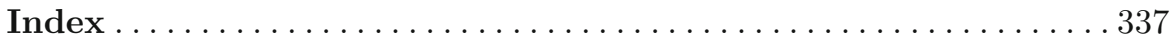

